\title{
Study on the Mechanical Properties of the Surface Layer Thickness and
}

\section{the Viscoelastic Properties of the Geothermal Regeneration}

\author{
Jiangang Qiao ${ }^{1, a^{*}}$, Xiaomin Liu $^{2, b}$ \\ ${ }^{1}$ School of Civil Engineering , Hebei University of Technology , Tianjin 300401, China \\ ${ }^{2}$ School of Civil Engineering, Hebei University of Technology , Tianjin 300401, China \\ aqiaojg369@126.com, b1970351293@qq.com
}

Keywords: Regeneration layer thickness; ANSYS; 3D model

Abstract. Viscosity restrain the road performance of asphalt mixture with geothermal regeneration. In the design and construction of the geothermal renewable asphalt pavement, the thickness of the regenerated layer is one of the most important factors that affect the mechanical response of the material. In order to improve the road performance of the heat recovery asphalt pavement, ANSYS finite element analysis method is adopted to build the 3D model of asphalt pavement structure, and then the asphalt road structure of each layer is also analyzed. The change law of the thickness of the regenerated asphalt layer and the road surface deflection, and the thickness of there generated layer and the residual deformation are obtained. Moreover, the relationship between the thickness of the asphalt regeneration layer and the bending stress of the base is obtained, too. It is found that the thickness of the regeneration layer can reduce the damage of road structure layer, which lays a theoretical foundation for the design and construction of geothermal renewable asphalt pavement. And it can provide an idea for the viscoelastic mechanical response of recycled asphalt concrete pavement.

\section{Introduction}

In view of the viscoelastic properties of the heat regenerated asphalt, the domestic and foreign scholars have carried out some related researches. In 2013, Ali Hesham of the Florida International University College of urban and Environmental Sciences, sampled in implementation of Superpave criteria of pavement and hot mix asphalt paving pavement, and tested some road performance, such as, the hot in place recycling of asphalt mixture rutting, anti flood and low temperature resistance, and pointed out that the hot mix asphalt mixture can well meet the requirements of Superpave Asphalt road design, and long-term performance can be better than fresh asphalt paving pavement ${ }^{[1]}$. In 2013, Kassem Emad, Texas A\&M University, Texas Institute of transportation, through testing the axial and lateral strain under different load form, found that the viscoelastic Poisson ratio is not as long as the time of the previous scholars, but at the beginning of stress relaxation experiments with the gradual increasing of time, then stabilized ${ }^{[2]}$. In 2010, Kong Lingran, Dalian University of Technology, through the use of the old road extraction of Asphalt Extraction and analysis of its road performance, while based on the design of the mix proportion design of asphalt mixture, the high temperature stability and durability of asphalt mixture by experimental analysis, and thus determine the optimum asphalt content ${ }^{[3]}$. In 2013, Jiangsu Provincial Academy of Building Research Co., Ltd. Xujing et al, by changing hot recycled asphalt mixture of different regeneration agent dosage 
of Marshall properties and high temperature stability and other indicators, it is pointed out that the hot in place recycling mixture has the characteristics of "two high and two low" and adding recycling agent can significantly improve the anti water damage and crack resistance at low temperature ${ }^{[4]}$. Although domestic and foreign scholars mainly aimed at the low temperature cracking resistance of hot recycled asphalt in the low temperature, the different improvement schemes are proposed. However, because the viscoelastic properties is an important aspect of the performance of asphalt mixture, it is necessary to do further research and analysis.

\section{Building road structure 3D model}

ANSYS model parameter setting. Finite element method is used to set the model parameters of ANSYS viscoelastic Viscoelastic material using Prony series. The Prony series form of viscoelastic relaxation modulus is defined by the relaxation modulus of viscoelastic materials. Such as an equation1 :

$$
E(t)=E_{\infty}+\sum_{i=1}^{n_{E}} E_{i} \exp \left(-\frac{t}{\tau_{i}^{E}}\right)
$$

In the Ansys parameter input, the relaxation modulus $E(t)$ is expressed as the form of Prony series, the initial relaxation modulus $E_{0}$, Poisson's ratio $\mu$ and relative relaxation modulus $\alpha_{i}^{E}$ and relaxation time $\tau_{i}^{E}$ are analyzed. The mechanical response of asphalt pavement is calculated with ANSYS finite element analysis software.

Modeling. The choice of the road structure of the geothermal regeneration asphalt is shown in Fig.1. Using ANSYS finite element analysis software, the 3D model of asphalt pavement structure is established. Analysis of the N-MPa-mm system of units, of center model applied spacing 320mm wheel load, wheel loads take $213 \mathrm{~mm}$ diameter, pressure $0.7 \mathrm{MPa}$ circular load, asphalt road model in the horizontal direction were taken $6000 \mathrm{~mm}, 5000 \mathrm{~mm}$ in the vertical direction, namely in the $\mathrm{x}$, $\mathrm{y}$ and $\mathrm{z}$ direction length respectively $6000 \mathrm{~mm}, 5000 \mathrm{~mm}$ and $6000 \mathrm{~mm}$ to regeneration layer of $30 \mathrm{~mm}$, for example, the pavement structure can be divided into 266400 units, a total of 12325 node, as shown in Fig.2 :

\begin{tabular}{|c|}
\hline Overlay layerSMA-10 $20 \mathrm{~mm}$ \\
\hline RegenerationSMA-13 $30-40 \mathrm{~mm}$ \\
\hline SMA-13 $30 \mathrm{~mm}$ \\
\hline AC-20I $\quad 50 \mathrm{~mm}$ \\
\hline AC-25I $\quad 60 \mathrm{~mm}$ \\
\hline Cement stabilized crushed stone190mm \\
\hline Cement stabilized crushed stone190mm \\
\hline Graded broken stone $200 \mathrm{~mm}$ \\
\hline Soil foundation \\
\hline
\end{tabular}

Fig.1 A sketch map of the structure of the road structure of the geothermal regenerated asphalt

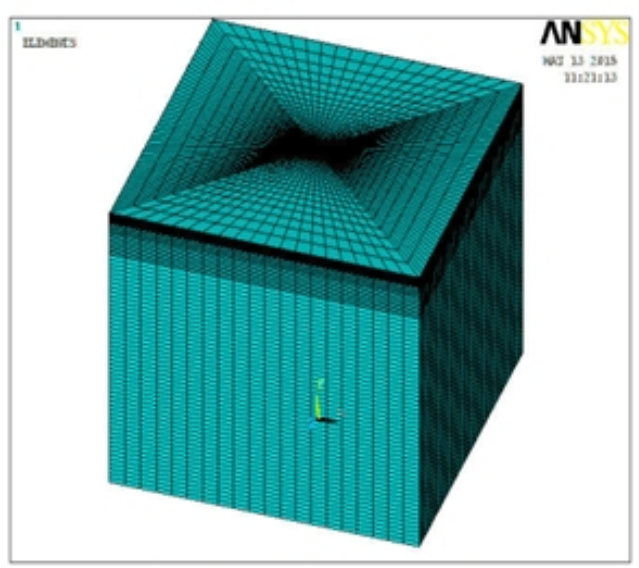

Fig.2 Unit mesh division

\section{Analysis of recycled asphalt layer thickness on surface deflection}

Through the analysis of asphalt pavement structure of 3D models, vertical deflection of the road 
surface contour images is shown in Fig.3. Layer thickness in different regeneration Center road wheel track point flexure under pulse load half-sine wave load changes are shown as in Fig.4:

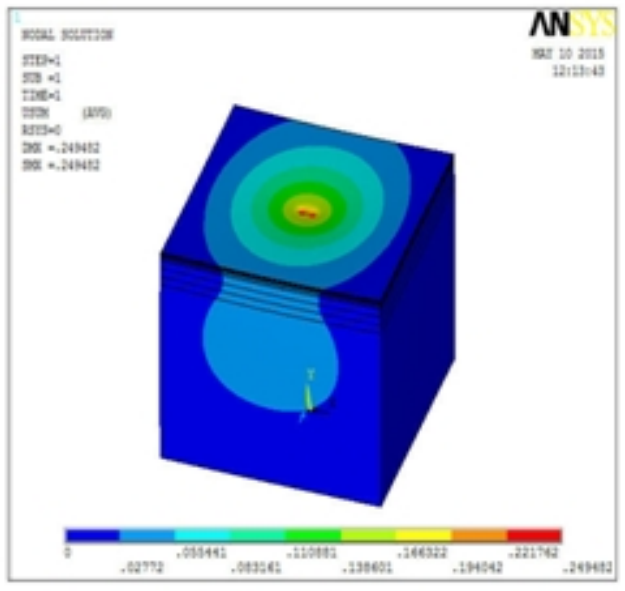

Fig.3 Contour map of road surface deflection

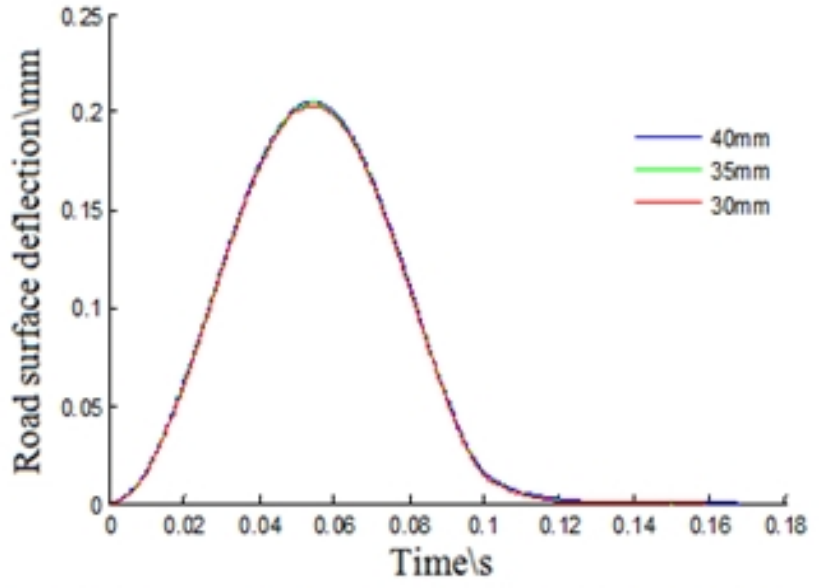

Fig. 4 The change of road surface deflection with time under different regeneration layer thickness

Fig.4 shows that in 0.1086s under half-sine wave load time, maximum deflection pavement changes half-sine wave form load, When $t=0.05 \mathrm{~s}$ is $0.1086 \mathrm{~s}$, the maximum deflection of the road surface is 0.2047 . When more than $0.1086 \mathrm{~s}$, the load is over, the residual deformation occurs, and the deflection value tends to zero as time goes by.

At the same time, the thickness of the residual deformation and the time of the residual deformation regression to zero are obtained, and the results are shown in Table 1:

Table 1 Residual response of different regeneration layer thickness

\begin{tabular}{cccc}
\hline $\begin{array}{c}\text { Regeneration } \\
\text { layer } \\
\text { thickness(mm) }\end{array}$ & $\begin{array}{c}\text { Surface } \\
\text { deflection } \\
(\mathrm{mm})\end{array}$ & $\begin{array}{c}\text { Residual deformation at the } \\
\text { end of stress (mm) }\end{array}$ & $\begin{array}{c}\text { Residual deformation } \\
\text { regression to zero time (s) }\end{array}$ \\
\hline 30 & 0.2047 & 0.00740 & 0.1681 \\
35 & 0.2034 & 0.00731 & 0.1592 \\
40 & 0.2026 & 0.00719 & 0.1505 \\
\hline
\end{tabular}

The results shows that the more the regeneration layer thickness, the smaller the residual response, and the shorter the time of residual response to zero.

The change of the road surface deflection under different regeneration thickness and the time variation of residual deformation regression to zero are shown in Fig.5 and Fig.6 :

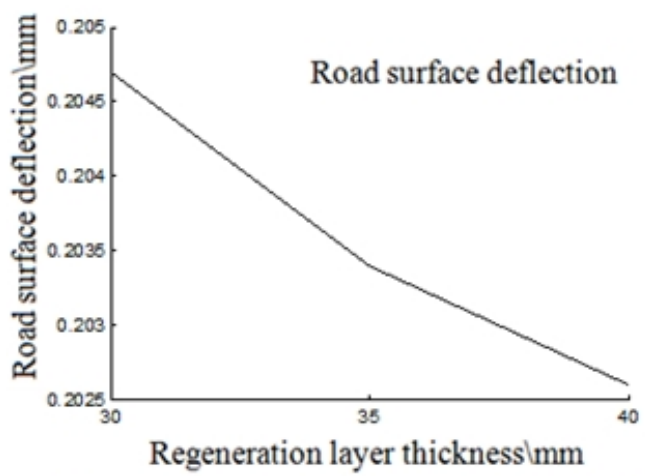

Fig.5 Road surface deflection under different regeneration layer thickness

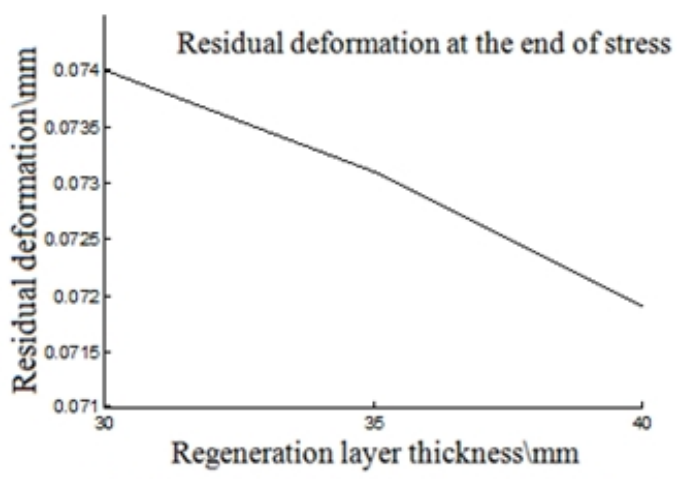

Fig.6 Residual deformation under different regeneration layer thickness

From Fig.5 and Fig.6, we can see that the deflection of the road surface and the residual 
deformation decrease with the increase of the thickness of the recycled layer. When the regeneration layer thickness is less than $35 \mathrm{~mm}$ and more than $35 \mathrm{~mm}$, the side of the road is faster, but the residual deformation decreases slowly.

The time variation of the residual deformation regression to zero with different thickness is shown in Fig.7. The deflection of the bending in the $0.63 \mathrm{~s}$ reaches the maximum value, and the deflection of the road surface under different regeneration layer thickness is shown in Fig.8.

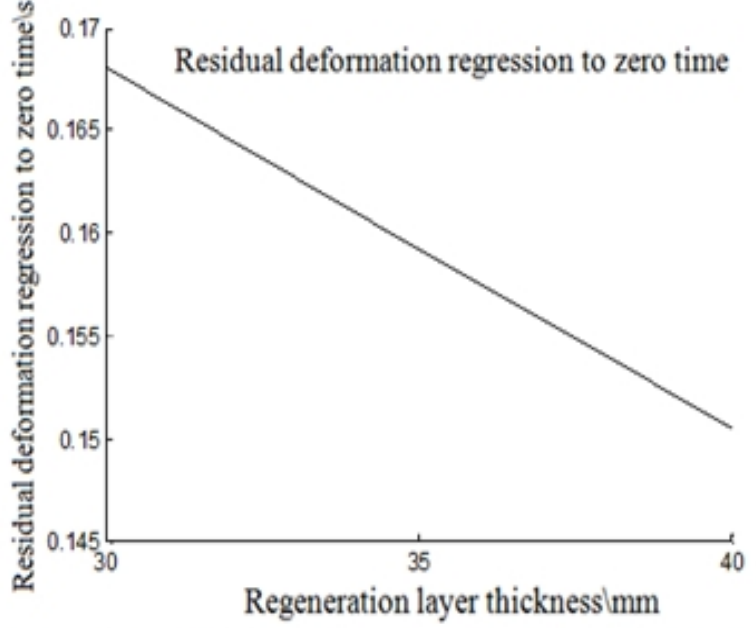

Fig.7 Time variation of residual regression to zero

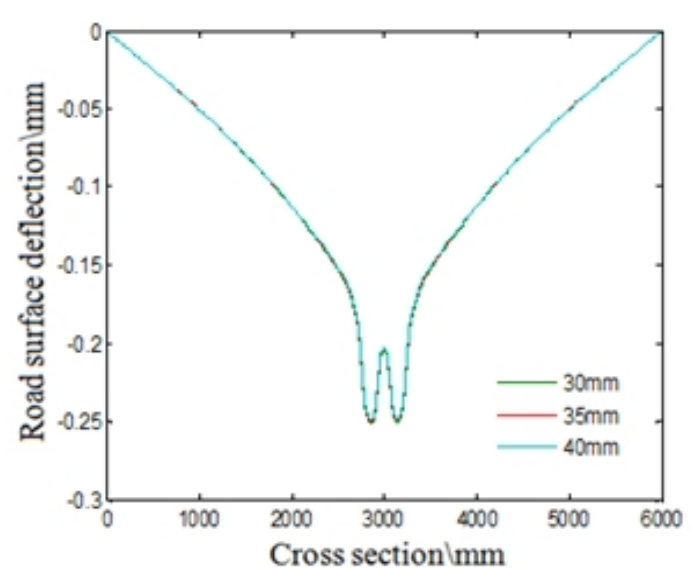

Fig.8 Surface deflection curves of the deformation regenerated layer thickness

From Fig. 7 we can see that the time of the thickness of the regenerated layer and the time of the regression to the zero are linear, the bigger the thickness of the regeneration layer is, the shorter the time returning to zero.

Fig.8 shows that in the peak moment of surface deflection, dynamic loading wheel Clearance Center-crossing points on the cross section of road surface deflection as the regeneration layer thickness significantly different regeneration layer thicker. The greater the thickness of the raw layer, smaller surface deflection. And in the round gap center point and load center point to increase the regeneration layer thickness is significantly to reduce the deflection of pavement surface viscoelastic response effect.

\section{Effect of thickness of recycled asphalt layer on the tensile stress of structure layer}

Established by the road surface in vertical downward path, through investigating deflection corresponding to peak time under different regeneration layer thickness tensile stress, it can be seen that the end of all layers layer is shown in Fig.9. Due to our specification the asphalt layer and base layer of tensile stress as one of the design indexes of asphalt road design, through studying asphalt layer and base layer of bending stress values, it is found that asphalt layer of the tensile stress is compressive stress and meets regulatory requirements, analysis of base layer thickness and tensile stress at the end of the relationship, as shown it is in Fig.10 below: 


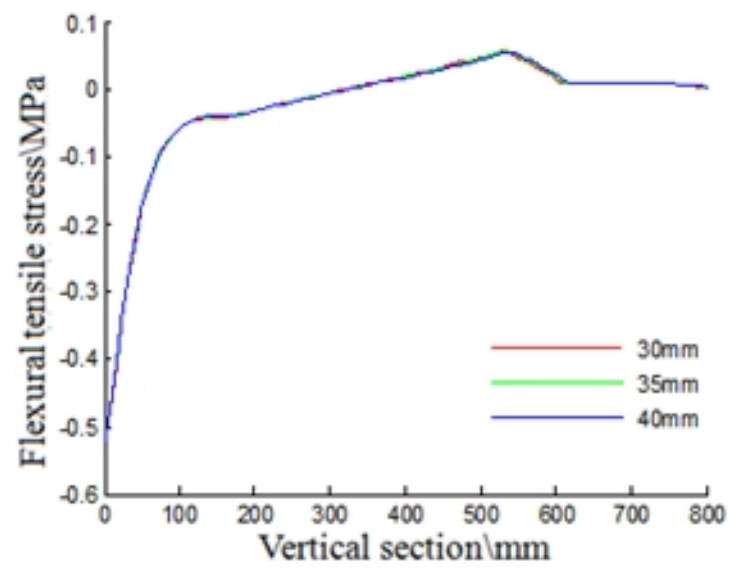

Fig.9 Layer bottom bending stress under regeneration layer thickness

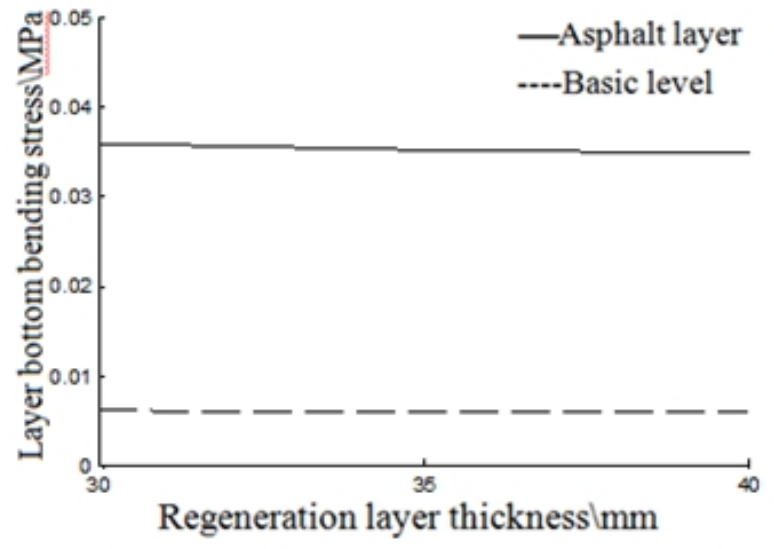

Fig.10 Different regeneration different layer thickness lower end bending stress

From Fig.9 we can see: in the longitudinal section, with the increase of depth, the bottom bending stress at the beginning is negative, and the structure of the bottom of the pressure can meet the standard requirements. When the depth of the vertical section is less than $100 \mathrm{~mm}$, the stress decreases sharply with the increase of the depth; Between $100 \mathrm{~mm}-200 \mathrm{~mm}$, the bending stress decreases and the amplitude decreases ; When close to the bottom of the bottom layer of the bottom layer of the $320 \mathrm{~mm}$, the negative value is changed to a positive value ; with surface layer following depth of increased, bent pulled stress gradually reduced to zero, and keep constant layer end of bent pulled stress with regeneration layer thickness of increases and reduced, Increasing regeneration layer thickness of recycled asphalt pavement structure damage can be reduced.

\section{Conclusions}

Through the viscoelastic properties of asphalt concrete materials, the road signs of the thermal regeneration and the viscoelastic mechanical response of the pavement under different regeneration layers are analyzed. It can be known that the bigger the regeneration layer thickness, the smaller the surface deflection of the road surface, the smaller the residual response, the shorter the time to zero, and the smaller the bottom bending stress. The more the regeneration layer thickness is described, the smaller the road of the vehicle load on the road regeneration is.

\section{Reference documentation}

[1] Ali, Hesham1,McCarthy, Leslie Myers, Welker Andrea. Performance of hot in-place recycled Superpave mixtures in Florida. Construction and Building Materials[J].2013.618-626.

[2] Kassem Emad, Grasley, Zachary C.,Masad, Eyad.Viscoelastic poisson's ratio of asphalt mixtures[J].International Journal of Geomechanics .

162-169.

[3] Lingran Kong. Study on the durability of asphalt mixture with geothermal regeneration [D].DaLian : Dalian University of Technology. 2010.In Chinese.

[4] Jing $\mathrm{Xu}$, Jiaping Liu, Jinxiang Hong. Effect of regeneration agent on the performance of heat regeneration mixture [J].Highway. 2013.290-293. In Chinese. 